International Journal of Engineering \& Technology, $7(3.34)(2018) 30-35$
International Journal of Engineering \& Technology
SPC
Website: www.sciencepubco.com/index.php/IJET
Research paper

\title{
Strengthening of Reinforced Concrete Beam Elements by Wrapping with Gfrp
}

\author{
Dr. Tamil Selvi ${ }^{1}$, Dr. P.B. Sakthivel ${ }^{2}$, R. PoornimaGandhi ${ }^{3}$ \\ ${ }^{I}$ Professor, Department of Civil Engineering, Vel Tech High Tech Dr. Rangarajan Dr. SakunthalaEngineering College \\ ${ }^{2}$ Professor of Structural Engineering, Vel Tech High Tech Dr. RangarajanDr.SakunthalaEngineering College \\ ${ }^{3}$ M.E II Year Structural Engineering Vel Tech High Tech Dr. Rangarajan Dr. Sakunthala EngineeringCollege
}

\begin{abstract}
Structural elements need to strengthening and retrofitting works as a result of ageing, upgrading of structure due to new design codes or any Environmental issues. The strengthening or retrofitting of existing structures are done externally to the structural members using various techniques such as jacketing, retrofitting, guniting and shotcreting, and ferrocement techniques. The experiment is carried out to increase the load carrying capacity of structure by wrapping externally the beam elements with Glass Fibre Reinforced Polymer mats (GFRP) is wrapped around the beam elements. The load carrying capacity is analysed using single and double layer wraps on damaged and undamaged specimens and compare with conventional beam as control specimens. Beam specimens of size $750 \mathrm{~mm} \times 150 \mathrm{~mm} \times 150 \mathrm{~mm}$ with M30 Grade concrete used in the experiment. The result of flexural strength and load - deflection of test and control beam have brought out with energy absorption coefficient. The study results have demonstrated that the performance of 1 layer GFRP wrapped beams show an increased load carrying capacity of 1.86 times of that of conventional beam, and 2 layer GFRP wrapped beam show an increase in load capacity of 2.6 times of that of conventional concrete.
\end{abstract}

Keywords: Concrete, Energy absorption, Flexural Strength, Glass Fibre Reinforced Polymer,

\section{Introduction}

Mostly advanced materials are using in some of the fields such as automotive, aerospace and marine technologies due to their beneficial properties such as high strength, stiffness, durability fatigue, corrosion resistance, etc., Beams are the structural members that support Slabs, staircases, etc., The strengthening of existing beam in a structure requires strengthening which are constructed in the past using the older design codes in different parts of the world are structurally unsafe according to the new design codes. Strengthening has become the acceptable way of improving their load carrying capacity.

"Vishnu Jariwala et al [1]" have studied about resistance of the torsion of the beam using FRP laminates. It results in improvement of the torsional resistance of reinforced concrete beams. Two beams are taken as control specimens and eight beams are strengthened by Glass Fiber Reinforced Polymer (GFRP) wrapping of different configuration. All beams are subjected to combined effect of torsion and bending. A loading frame and test set up are fabricated for applying combined torsion and bending. Angle of twist at interval of torque, torque at first crack, ultimate torque are compared for control and strengthened beam.

"AmrulKaish et al., [2]" have discussed the jacketing techniques for strengthening of structural members two different approaches are taken into account; i.e. (a) strengthen all the corners, and (b) reducing stress concentrations at corners. Test results and crack pattern shows that, both approaches are effective to overcome the stress concentration problem of square jacketing. However, the Strengthening of all corners is practically more suitable than the reducing stress concentrations at corners.

"OndřejHolčapek et al., [3]" have conducted experiments on strengthening of brick masonry columns by thin layer of textile reinforced micro concrete. it leads to increase in the load capacity due to significant concentration of tensile stresses in the corners of column. Another set of masonry columns were prepared modified shape of the cross-section by cutting off approximately $30 \mathrm{~mm}$ of the corners. Polygonal cross-section shape of the columns brought more effective utilization of the reinforcing layers and significant increasing of the structure load capacity.

"Nasr Hassan et al [4]" Transverse openings are provided through reinforced concrete beams to accommodate utility ducts and pipes and analyzed through the FEM software (ANSYS) Strengthening of all beams with opening came out to six types of different scheme around the opening using fiber-reinforced polymer(FRP). Scheme (i) is vertical and horizontal carbon fiber sheets around the opening, scheme (ii) is inclined at 45 _ carbon fiber sheets around the opening in addition to horizontal. The failure loads, crack pattern, strain progress, mode of failure and energy absorption are studied and allayed using ANSYS software.

"Sudhakar and Partheeban [5]" have carried out the investigation on wrapping of reinforced concrete columns with GFRP caused increasing of ductility and compressive strength of Reinforced 
Cement Concrete(RCC) columns. GFPR shows control in Compression region and has no affected on tension control region of RCC columns. They demonstrated that it is possible to strengthen the compressive strength of RCC columns with GFRP.

\section{Experimental Procedure}

\subsection{Materials}

Cubes and beams are casted of standard size in which cubes are tested for compressive strength and beams are tested for the flexural strength.

\subsection{GFRP Properties}

Fiber Glass is a type of fiber-reinforced plastic where the reinforcement fiber is specifically glass fiber. The glass fiber may be randomly arranged, flattened into a sheet (called a chopped strand mat), or woven into a fabric. The plastic matrix may be a thermosetting plastic - most often epoxy, polyester resin - or vinyl ester, or a thermoplastic. The fig. 1 shows the GFRP mat. Table 1 shows the physical properties of GFRP.

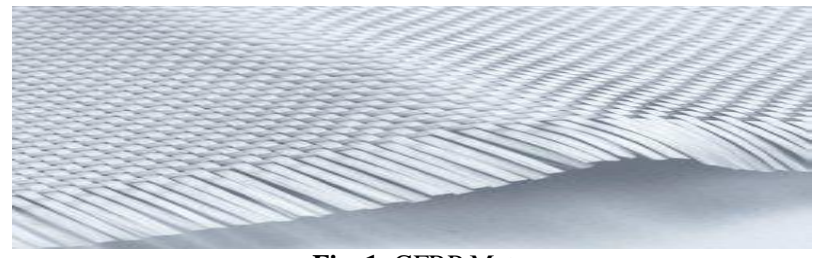

Fig. 1: GFRP Mat

The advantages of FRP are many such as high strength-to-weight ratio, high specific tensile strength, good fatigue resistance, ease of installation and corrosion resistance characteristics, ease of repairing, high strength in the required direction, and higher ultimate strength and lower density than steel, etc. are some of the properties which make FRPs ideal for strengthening applications. But a good amount of theoretical knowledge and design guidelines is required to ensure a safe, reliable and cost-efficient use of FRP materials. Carbon fibre composites are the most frequently used system in previous research and retrofitting field applications "(El-Ghandour, 2011; Barros et al., 2007; Esfahani et al., 2007; Al-Rousan and Issa, 2011; Hashemi and Al-Mahaidi, 2012)". [8,9,10,11,12].

Table 1: Properties of GFRP

\begin{tabular}{|l|l|}
\hline Property & Value \\
\hline Density & $1800 \mathrm{~kg} / \mathrm{m} 3$ \\
\hline Young's modulus & $26 \mathrm{gpa}$ \\
\hline Elongation at break & $2 \%$ \\
\hline Tensile strength & $530 \mathrm{mpa}$ \\
\hline Thermal expansion & $19 \times 10^{-6}$ \\
\hline Poisson's ratio & 0.28 \\
\hline
\end{tabular}

\subsection{Epoxy Resin and Hardener}

Epoxy Resins - LY556 and Hardener HY951 are using as the bonding material to the beam surface and Glass fibre polymer mat in the ratio of 10:1.

\subsection{Experimental Procedure}

The main objective of the study is to compare the effectiveness of the GFRP for damaged and undamaged beam specimen of uniaxial and biaxial layers wraps of GFRP in terms of flexural strength and Energy absorption.

\subsection{Beam Casting and Retrofitting}

Casting: Totally 9 beams were casted of M30 grade concrete of side $700 \mathrm{~mm} \times 150 \mathrm{~mm} \times 150 \mathrm{~mm}$. The beams are reinforced with $4-10$ $\mathrm{mm}$ diameter bars in longitudinal direction and $8 \mathrm{~mm}$ diameter stirrups in the transverse direction spaced at $100 \mathrm{~mm} \mathrm{c} / \mathrm{c} .3$ beams are taken as control beams. 2 beams are wrapped with uniaxial layer of GFRP and other 2 beams are wrapped with biaxial layer of GFRP mats.

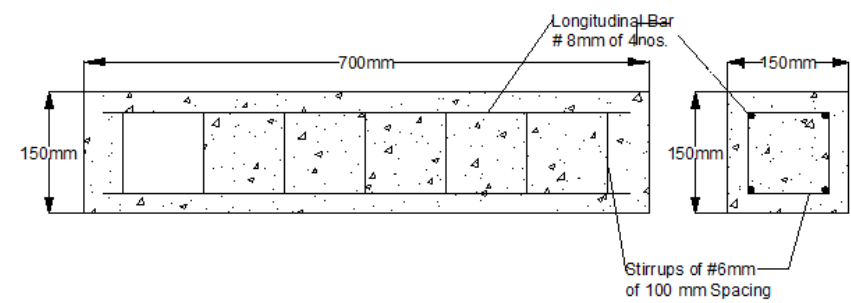

Fig.2: Reinforcement Detailing

\subsection{Retrofitting Scheme:}

The beam surface was then made rough and cleaned to remove any dust particles. The epoxy resin was mixed with hardener as per manufacture's instruction. Resin: Hardener ratio is 10:1 in a container. After uniform mixing the beam surface was applied with two coats of the mixed solution of epoxy resin.

The fibre sheet was cut to required size. Then the GFRP sheet was placed over the surface of 1 layer for 3 samples and 2 layers of 3 samples. Another coating of the resin mix was applied and then the specimen was left to dry for 5 days.

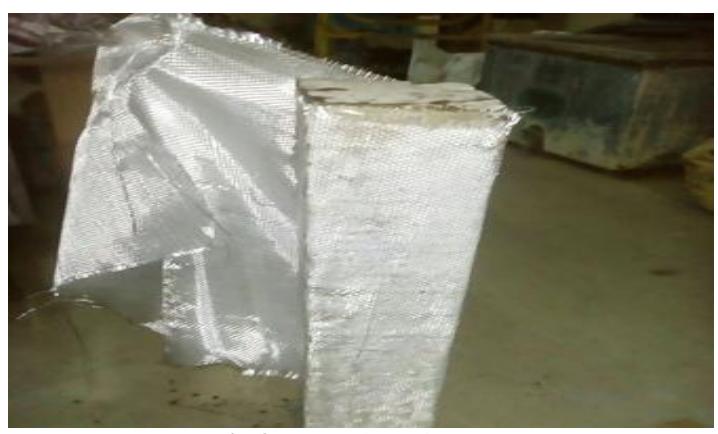

Fig.3: Wrapping of GFRP

\subsection{Test Setup}

All the beam specimen were tested under load and deflection. The readings were chronicled in digital deflect meter with load. The specimen is tested under two point loading of simply supported. The test setup is shown in figure 4

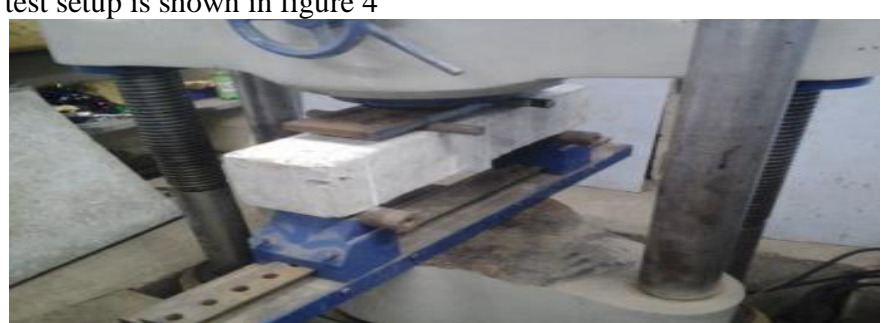

Fig. 4: Testing of control beam specimen 


\subsection{Note:}

$\mathrm{CB}$ - Control Beam

UDSL - Undamaged Single Layer wrapped beam

UDDL - Undamaged Double Layer wrapped beam

DSL - Damaged single layer wrapped beam.

DDL - Damaged double layer wrapped beam.

\section{Step 1: Control Beam (CB)}

Totally two control beams are tested using load and deflection curve flexural strength and energy absorption is intent.

Flexural strength: $\mathrm{CB}_{1}$ illustrates an initial crack in $32.3 \mathrm{KN}$ in the deflection of $6.93 \mathrm{~mm}$ and ultimate load on $56.30 \mathrm{KN}$ with $9.53 \mathrm{~mm}$ deflection. $\mathrm{CB}_{2}$ indicates the initial crack in $30 \mathrm{KN}$ with the deflection of $6.85 \mathrm{KN}$ and ultimate load on $55.80 \mathrm{KN}$ with $9.67 \mathrm{~mm}$ deflection.

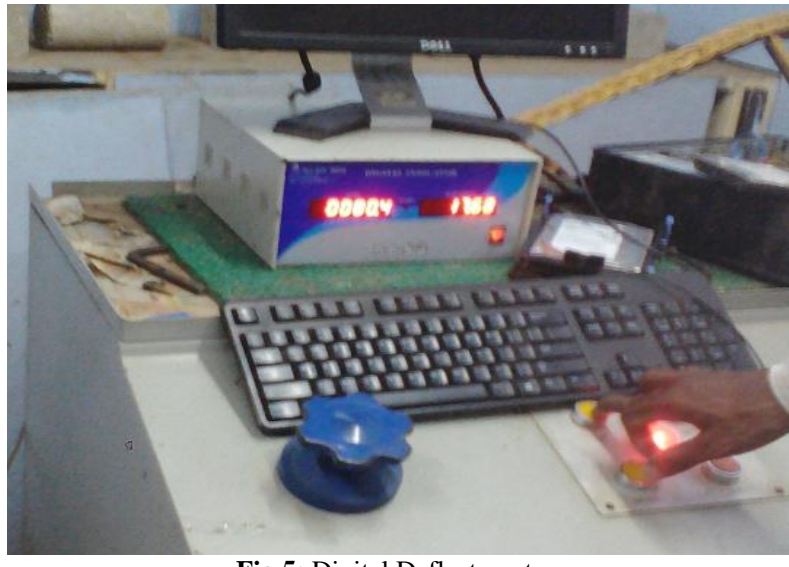

Fig 5: Digital Deflectometer

Energy Absorption: The energy absorption is the area under which load and deflection curve. The typical value beam specimen (CB1 and CB2) is considered for energy absorption curve.

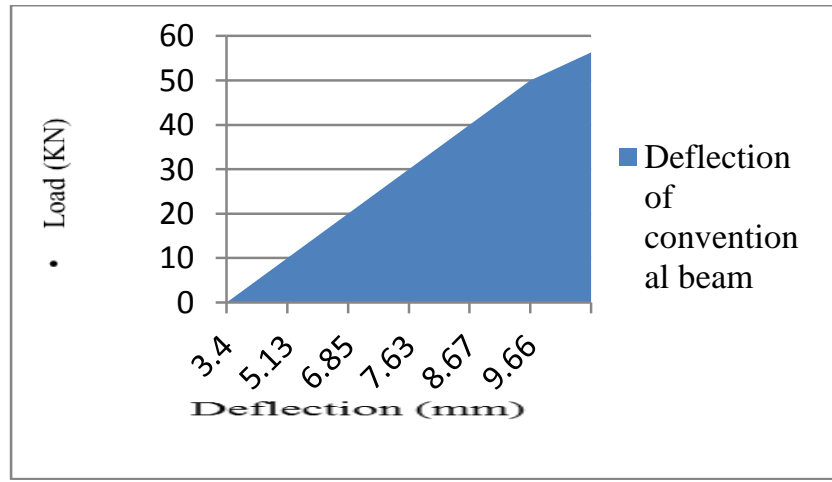

Fig 6: Energy Absorption of Control Beam

The area of energy absorption for control beam specimen is arrived is $314.18 \mathrm{KN} \mathrm{mm}$.

\section{Step 2: Undamaged Single GFRP Wrap (UDSL)}

Totally two UDSL are tested using load and deflection cure flexural strength and energy absorption is intent.

Flexural strength: since the beam is wrapped with GFRP mat the initial crack is indiscernible. UDSL1 illustrates an ultimate load on $112.36 \mathrm{KN}$ with $13.86 \mathrm{~mm}$ deflection. UDSL2 indicates ultimate load on $113.02 \mathrm{KN}$ with $14.07 \mathrm{~mm}$ deflection.

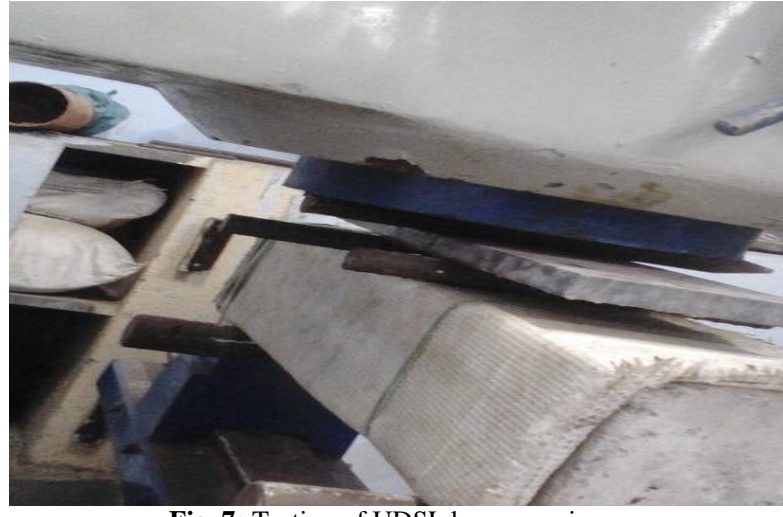

Fig. 7: Testing of UDSL beam specimen

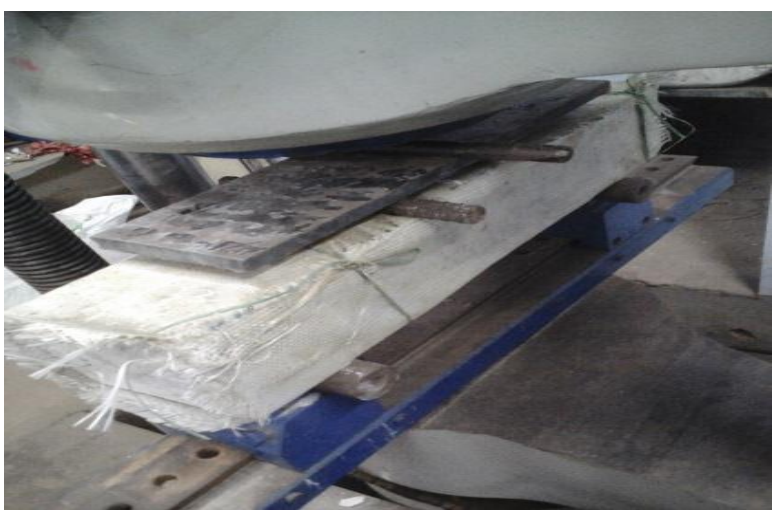

Fig.8: Testing of UDDL beam specimen

Energy Absorption: The typical value beam specimen (UDSL1and UDSL2) is considered for energy absorption using load and deflection curve.

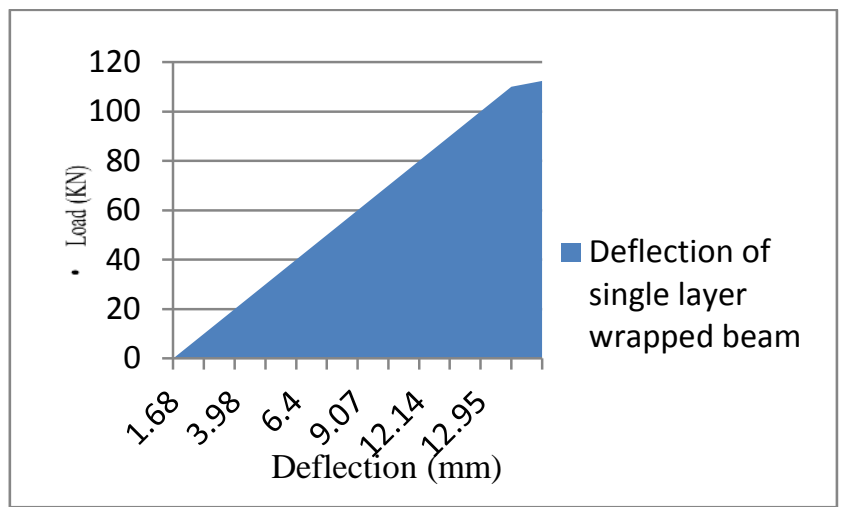

Fig. 9: Energy Absorption curve of UDSL

The area of energy absorption arrived is $817.43 \mathrm{KN} . \mathrm{mm}$.

The energy absorption coefficient of undamaged single layer wrapping to Control beam is 2.60 . The energy absorption coefficient of UDSL is 2.60 times of CB and 1.30 times of DSL.

\section{Step 3: Undamaged Double GFRP Wrap (UDDL)}

Totally two undamaged double Layer GFRP wrapped beams are tested using load and deflection curve flexural strength and energy absorption is found.

Energy Absorption: The typical value beam specimen (UDDL1and UDDL2) is considered for energy absorption using load and deflection curve. 


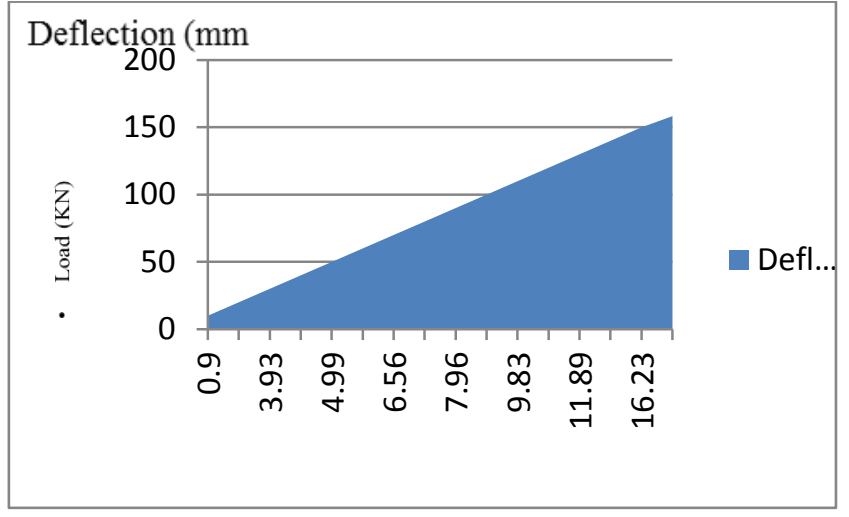

Fig 10: Energy Absorption of UDDL

The area of energy absorption arrived is 1203.48 KN.mm. The energy absorption coefficient of Undamaged Double layer wrapping to Control beam is 3.82 and 1.85 times of DDL.

\section{Step 4: Damage Single GFRP Wrap (DSL)}

Totally two DSL are tested using load and deflection cure flexural strength and energy absorption is intent.

Flexural strength: since the beam is wrapped with GFRP mat the initial crack is indiscernible.UDSL1 illustrates an ultimate load on $61.2 \mathrm{KN}$ with $11.42 \mathrm{~mm}$ deflection. UDSL2 indicates ultimate load on $60.87 \mathrm{KN}$ with $11.36 \mathrm{~mm}$ deflection.

Energy Absorption: The typical value beam specimen (DSL1and DSL2) is considered for energy absorption using load and deflection curve.

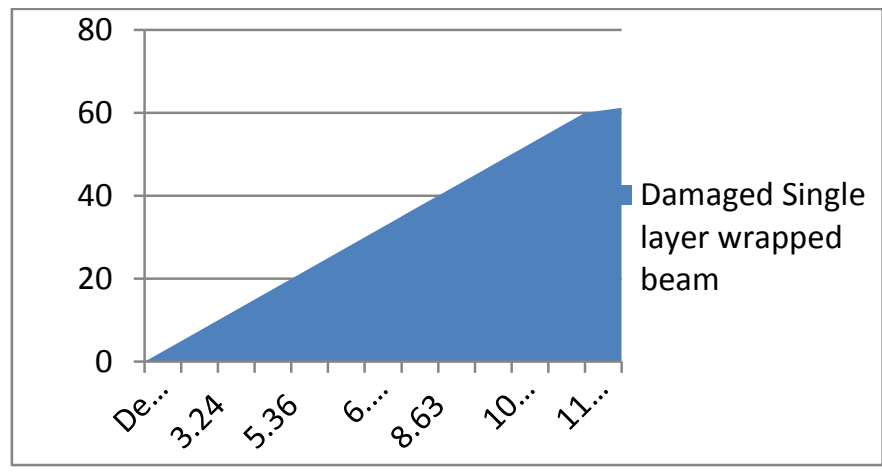

Fig 11: Energy Absorption of DSL

The area of energy absorption arrived is $410.37 \mathrm{KN} . \mathrm{mm}$. The energy absorption coefficient of Undamaged Single layer wrapping to Control beam is 1.306 .

\section{Step 5: Damage Double GFRP Wrap (DDL)}

Totally two DDL are tested using load and deflection cure flexural strength and energy absorption is intent.

Flexural strength: Since the beam is wrapped with GFRP mat the initial crack is indiscernible. DBL1 illustrates an ultimate load on $80.6 \mathrm{KN}$ with $18.52 \mathrm{~mm}$ deflection. DDL2 indicates ultimate load on $80.2 \mathrm{KN}$ with $18.90 \mathrm{~mm}$ deflection whereas DDL3 indicates 80.75 with 18.35 mmdeflection.

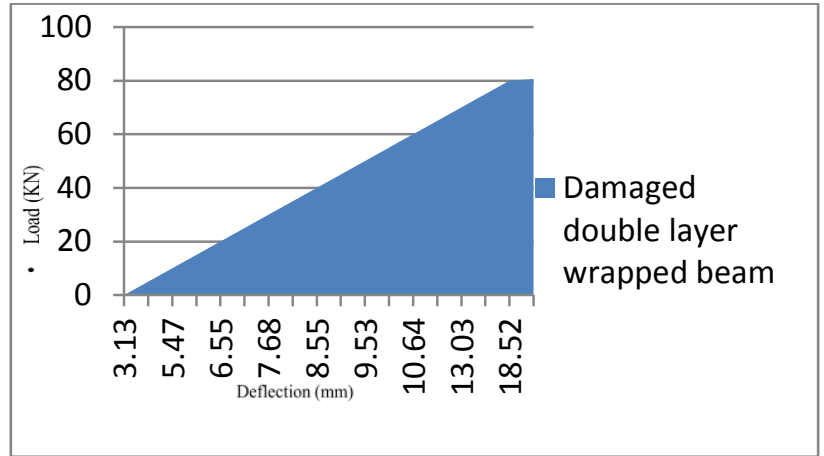

Fig 12: Energy Absorption of DDL

Energy Absorption: The typical value beam specimen (DDL1and DDL2) is considered for energy absorption using load and deflection curve.The area of energy absorption arrived is $410.37 \mathrm{KN}$.mm. The energy absorption coefficient of Undamaged double layer wrapping to Control beam is 2.06 and 1.58 times of DSL beam.

\section{Results and Discussions}

\subsection{Flexural Strength}

The beams are tested for the flexural loading and the reading for load and are deflection is noted.

Table 2: Flexural Strength of beam

\begin{tabular}{|l|l|l|l|}
\hline S.No & Type of Beam & $\begin{array}{l}\text { Ultimate } \\
\text { Load }\end{array}$ & Flexural Strength \\
\hline 1 & Control Beam & 52.30 & $13.45 \mathrm{~N} / \mathrm{mm}^{2}$ \\
\hline 2 & $\begin{array}{l}\text { Single layer wrapped } \\
\text { beam }\end{array}$ & 113.02 & $17.62 \mathrm{~N} / \mathrm{mm}^{2}$ \\
\hline 3 & $\begin{array}{l}\text { Double Layer wrapped } \\
\text { beam }\end{array}$ & 158 & $25.3 \mathrm{~N} / \mathrm{mm}^{2}$ \\
\hline
\end{tabular}

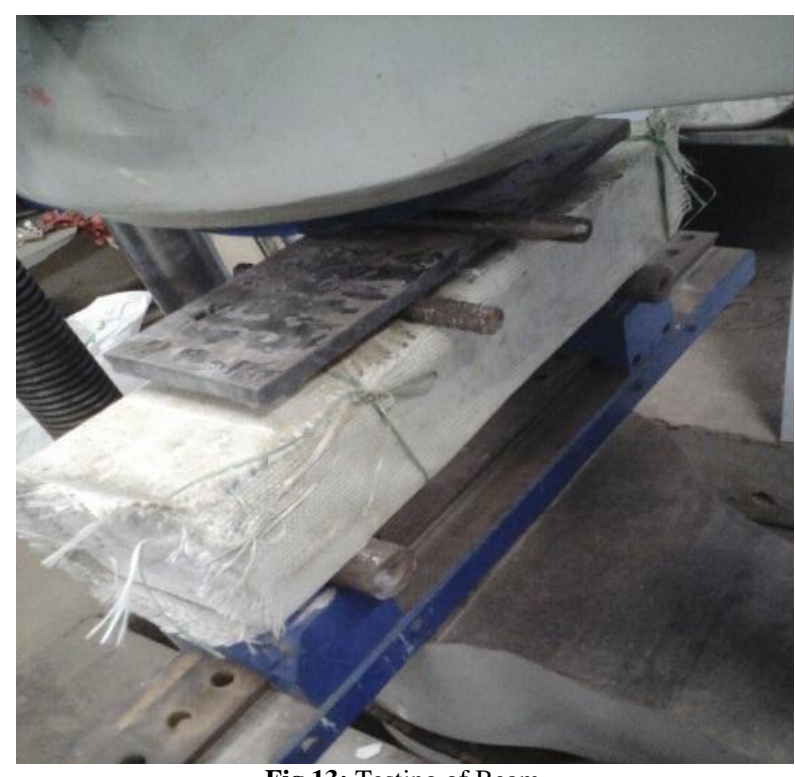

Fig.13: Testing of Beam

The load deflection curve shows that, the maximum load carrying capacity is attained when the beam is wrapped double layer of GFRP. The flexural strength of Double layer wrapped GFRP beam shows increased in load carrying capacity of 2.6 times of control beam and the Single layer wrapped RC beam shows the increase in load carrying capacity of 1.86 times of Control beam. 


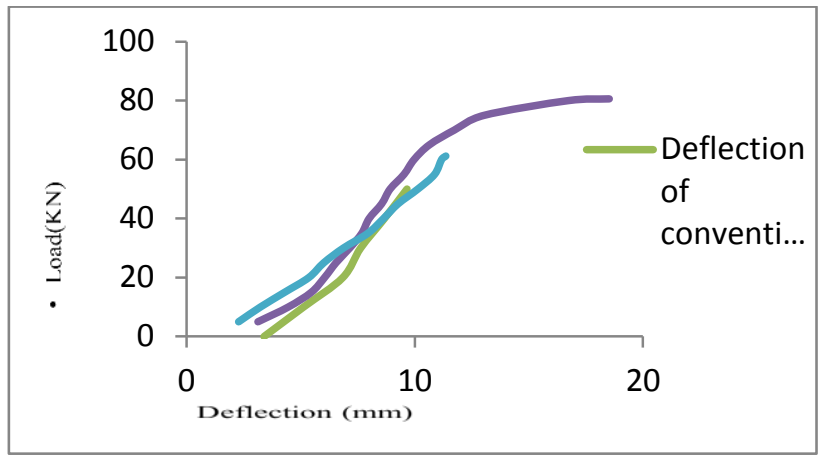

Fig. 14: Load deflection curve of damaged beam wrapped with GFRP

Table 3: Load and deflection of damaged beam

\begin{tabular}{|l|l|l|l|}
\hline S.No & Type of beam & Failure load & Deflection \\
\hline 1 & CB & 56.30 & 9.045 \\
\hline 2 & DSL & 61.02 & 11.36 \\
\hline 3 & DDL & 80.6 & 17.69 \\
\hline
\end{tabular}

Table 4: load and deflection undamaged beam

\begin{tabular}{|l|l|l|l|}
\hline S.No & Type of Beam & Failure load & Deflection \\
\hline 1 & CB & 56.30 & 9.045 \\
\hline 2 & UDSL & 113.02 & 14.07 \\
\hline 3 & UDDL & 158.6 & 17.29 \\
\hline
\end{tabular}

Flexural strength of undamaged beam when strengthened using GFRP of single and double layer shows maximum response when compared to the control beam. Undamaged beam wrapped with double layer of GFRP shows an increase in flexural strength of 2.7 times of control beam and 1.3 times increase in undamaged beam wrapped with single layer of GFRP. Whereas the undamaged beam when wrapped with singlelayer of GFRP shows a 2.1 times increased in flexural strength.

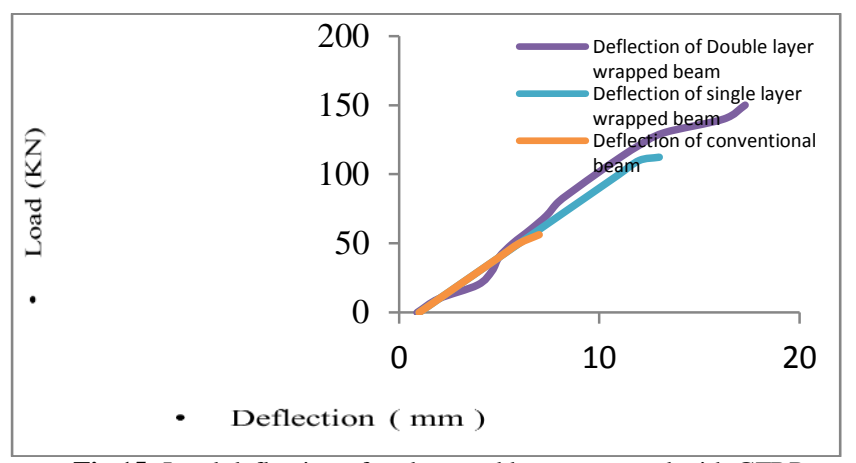

Fig.15: Load deflection of undamaged beam wrapped with GFRP

Table .5: Comparison of Flexural strength and Energy absorption

\begin{tabular}{|c|c|c|c|c|}
\hline & \multicolumn{2}{|c|}{ Flexural strength $\left(\mathrm{N} / \mathrm{mm}^{2}\right)$} & \multicolumn{2}{|c|}{$\begin{array}{l}\text { Energy Absorption Factor } \\
\text { (kNmm) }\end{array}$} \\
\hline S.No & Damaged & Undamaged & Damaged & Undamaged \\
\hline $\begin{array}{l}\text { SL/ } \\
\text { CS }\end{array}$ & 1.08 & 2.15 & 1.30 & 2.60 \\
\hline $\begin{array}{l}\mathrm{DL} / \\
\mathrm{CS}\end{array}$ & 1.43 & 3.05 & 2.06 & 3.82 \\
\hline $\begin{array}{l}\mathrm{DL} / \\
\mathrm{SL}\end{array}$ & 1.32 & 1.39 & 1.57 & 1.47 \\
\hline
\end{tabular}

Table .6: comparison of damaged and undamaged beam

\begin{tabular}{|c|c|c|c|l|l|l|}
\hline & \multicolumn{3}{|c|}{ Flexural strength(N/mm $\mathbf{m}^{2}$} & \multicolumn{3}{|c|}{ Energy Absorption Factor } \\
\hline S.No & $\begin{array}{c}\text { Damaged } \\
(1)\end{array}$ & Undamaged(2) & $(2 / 1)$ & $\begin{array}{l}\text { Damaged } \\
(3)\end{array}$ & $\begin{array}{l}\text { Unda } \\
\text { Maged } \\
(4)\end{array}$ & $(3 / 4)$ \\
\hline CS & 11.67 & 11.67 & 1 & 314.18 & 314.18 & 1 \\
\hline
\end{tabular}

\begin{tabular}{|l|l|l|l|l|l|l|}
\hline SL & 12.65 & 25.11 & 1.98 & 410.87 & 817.43 & 1.9 \\
\hline DL & 16.71 & 35.1 & 2.1 & 648.47 & 1203.4 & 1.8 \\
\hline
\end{tabular}

\section{Discussions}

The undamaged double layer GFRP wrapped beam specimen is considered for optimum result attains the flexural strength of 35.17 $\mathrm{N} / \mathrm{mm}^{2}$ is attained and the undamaged single layer GFRP wrapped beam specimen achieved a flexural strength of $25.11 \mathrm{~N} / \mathrm{mm}^{2}$. But the damaged single layer wrapped specimen attains a $12.65 \mathrm{~N} / \mathrm{mm}^{2}$ and damaged double layer wrapped specimen has $16.71 \mathrm{~N} / \mathrm{mm}^{2}$

"Sachin [6]" investigated on Jacketing of RC beams with the technique of using dowel connectors and micro-concrete, bonding agent and micro-concrete, combined use of dowel connectors, bonding agent and micro-concrete. The load carrying capacity of RC beam with smooth surface jacketed using dowel connectors and micro-concrete is $270 \mathrm{KN}, \mathrm{RC}$ beam with smooth surface jacketed using bonding agent and micro-concrete is $260 \mathrm{KN}$, RC beam with smooth surface jacketed using dowel connectors, bonding agent and micro-concrete $290 \mathrm{KN}$ and RC beam with smooth surface jacketed using only micro-concrete is $260 \mathrm{KN}$.

But the undamaged beam specimen wrapped with double layer and single layer of GFRP are $158.36 \mathrm{KN}$ and $112.6 \mathrm{KN}$ respectively whereas the load carrying capacity of damaged beam which attains the initial crack in the range of $33 \mathrm{KN}$. Load carrying capacity of the damaged beam wrapped with single and double layer of GFRP are 61.2 KN and 80.6 KN respectively

Zoiet, ET. al.,[7] have investigated about the comparison of Textile reinforced mortar and fiber reinforced polymer in shear strengthening of beams. The peak load of U- Wrapped jackets and Fully Wrapped jackets with Textile fiber is $78.2 \mathrm{KN}$ and $111.2 \mathrm{KN}$ respectively whereas FRP wrapping attains a peak load of $113.4 \mathrm{KN}$ and $150.3 \mathrm{KN}$ (Flexure).

The GFRP undamaged beam of double layer wrapped with FRP reaches the peak load of $158.36 \mathrm{KN}$ and single layer achieves 112.6 $\mathrm{KN}$.

\section{Conclusions}

Based on the experimental work carried on the study of Glass fibre reinforced polymer for improving the strength of RC beam the following conclusions are drawn

Undamaged beam - Single layer of GFRP (UDSL): strengthening of beam shows a flexural strength of $25.11 \mathrm{~N} / \mathrm{mm}^{2}$ which is 2.1 times of control beam and 1.65 times of damaged beam of Single layer GFRP. The ultimate load carrying capacity of the single layer wrapped undamaged beam specimen 1.7 times more than control beam.

Undamaged beam - double layer of GFRP (UDDL) : Strengthening of double layer undamaged beam shows an increase in flexural strength of 2.7 times the control beam i.e. $35.1 \mathrm{~N} / \mathrm{mm}^{2}$. The ultimate load carrying capacity of the beam is 2.81 times of control beam and 1.39 times of single layer un damaged beam. Whereas it provides the 1.9 times more strength that of damaged double layer wrapped beam.

Damaged - Single layer wrapped beam (DSL): The intensification of damaged beam is wrapped with single layer of GFRP shows a minimum increase in flexural strength of 1.08 times that of control beam with more deflection. 
Damaged - double Layer wrapped beam (DDL) : The intensification of damaged beam specimen with double layer of GFRP shows a flexural strength of 1.4 times that of control beam and 1.08 times of single layer wrapped GFRP specimen.

The energy absorption coefficient of UDDL shows more response than any other specimen i.e. 3.82 times of $\mathrm{CB}$ and 1.47 times of UDSL specimen.

It is concluded that the GFRP wrapping is more effective in both single layer and double layer wraps in strengthening of undamaged beam specimen. Hence it is mostly effective in strengthening of undamaged structural elements in case of updating the structure as per new codal provisions from new codal provisions. Retrofitting the damaged structural elements using both single and double layer both are effective but double layer wrapping of GFRP mats is more effective than single layer wrapping and hence double layer wrapping for damaged structure is preferable.

\section{References}

[1] Vishnu H. Jariwala, Paresh V. Patel, Sharadkumar P. Purohit., (2013) "Strengthening of RC Beams subjected to Combined Torsion and Bending with GFRP Composites", Elsevier, Procedia Engineering 51(2013 ) $282-289$.

[2] B. M. AmrulKaish, M. R. Alamb, M. Jamil and M. A. Wahed, (2013)., "Ferrocement Jacketing for Restrengthening of Square Reinforced Concrete Column under Concentric Compressive Load" Elsevier, Procedia Engineering 54 ( 2013 ) 720 - 7281877-7058 .The 2nd International Conference on Rehabilitation and Maintenance in Civil Engineering.

[3] OndřejHolcapek, Filip Vogel, PavelReiterman , (2015), "Using of Textile Reinforced Concrete Wrapping for Strengthening of Masonry Columns with Modified Cross-section Shape", Elsevier, Procedia Engineering 195

( 2017 ) $62-66$.

[4] Nasr Z. Hassan, Alaa G. Sherif, Amal H. Zamarawy ,(2015),'Finite element analysis of reinforced concrete beams with opening strengthened using FRP" Ain Shams Engineering Journal (2017) 8, 531-537.

[5] R. Sudhakar and Dr. P. Partheeban, (2017), "Strengthening of RCC Column Using Glass Fibre Reinforced Polymer (GFRP)".,International Journal of Applied Engineering Research ISSN 0973-4562 Volume 12, Number 14 (2017) pp. 4478-4483.

[6] Sachin S. Raval, Urmil V. Dave, (2013) "Effectiveness of Various Methods of Jacketing for RC Beams", Elsevier, Procedia Engineering 51 (2013) $230-239$.

[7] Zoi C. Tetta, Lampros N. Koutas, Dionysios A. Bournas, (2015) "Textile-reinforced mortar (TRM) versus fiber-reinforced polymers (FRP) in shear strengthening of concrete beams", Elsevier, Composites Part B 77 (2015) 338e348.

[8] M.R. Esfahani, M.R. Kianoush, A.R. Tajari,(2007), "Flexural behaviour of reinforced concrete beams strengthened by CFRP sheets", Engineering Structures, vol. 29, pp. 2428-2444.

[9] A.A. El-Ghandour (2011), "Experimental and analytical investigation of CFRP flexural and shear strengthening efficiencies of RC beams", Construction Building Materials, vol. 25pp. 1419-1429.

[10] R. Al-Rousan, M. Issa, (2011), "Fatigue performance of reinforced concrete beams strengthened with CFRP sheets", Construction Building Materials, vol. 25 pp. 3520-3529.

[11] S. Hashemi, R. Al-Mahaidi, "Flexural performance of CFRP textileretrofitted RC beams using cement-based adhesives at high temperature" Construction Building Materials, vol.28, pp. 791-797.

[12] Al-Amery, Riadh Al-Mahaidi, "Coupled flexural-shear retrofitting of RC beams using CFRP straps", Composite Structures, vol. 75 pp. 457-464. 